\title{
EVALUASI DAERAH IRIGASI BENGAWAN JERO KABUPATEN LAMONGAN
}

\author{
Aris Setiawan', Nur Azizah Affandy² \\ ${ }^{1}$ Program Studi Teknik Sipil Fakultas Teknik Universitas Islam Lamongan, \\ ${ }^{2}$ Fakultas Teknik Program Studi Teknik Sipil Univesitas Islam Lamongan, \\ email: nurazizah_5@yahoo.com
}

\begin{abstract}
Bengawan Jero Irrigation Area is located in the District Administration of Work Areas Karangbinangun, Lamongan.Objective of the research that for determine the level of damage that occurred in Bengawan Jero Irrigation Area and determine the priority scale rehabilitation of irrigation area of Bengawan Jero damage. Based on the analysis and discussion, analysis of priority rehabilitation of irrigation area of Bengawan Jero using Analytical Hierarchy Process $(A H P)$ give first priority to sub-system $05=0.68$. The next priority is a sub-system $07=0.44$, subsystem $01=0.23$, sub-system $09=0.70$, sub-system $03=0.25$, sub-system $10=0.42$, sub-system $11=0.65$, sub-system $06=0.52$, sub-system $08=0.54$, sub-system $04=0.50$ and last priority is the sub system $02=0.23$. Selection of rehabilitation alternatives tailored to the available funds. If the available funds are insufficient for the rehabilitation of irrigation area Bengawan overall Jero then rehabilitation can put emphasis on the primary channel only.
\end{abstract}

Keywords: Bengawan Jero, Analytical Hierarchy Process, rehabilitation alternatives

\section{PENDAHULUAN}

Daerah Irigasi Bengawan Jero terletak dalam Wilayah Kerja Administrasi Kecamatan Karangbinangun, Kabupaten Lamongan. Daerah Irigasi Bengawan Jero berada di bawah pengelolaan Satuan Kerja PSDA (Pengelola Sumber Daya Air) Bengawan Solo, Dinas PU Pengairan Propinsi Jawa Timur. Fungsi Daerah Irigasi Bengawan Jero adalah untuk mengairi sawah di kecamatan Karangbinangun. Sebagian dari lahan pertanian tersebut memperoleh air dari jaringan irigasi dan pembiayaan operasi dan pemeliharaan menjadi tanggung jawab pemerintah.

Dalam perkembangannya kerusakan yang terjadi di Daerah Irigasi Bengawan Jero tidak dapat diabaikan. Kerusakan-kerusakan yang terdapat di Daerah Irigasi Bengawan Jero antara lain pendangkalan saluran irigasi yang diakibatkan oleh sedimentasi. Longsornya saluran irigasi serta kerusakan pada bangunan utama, bangunan pengambilan, bagi dan sadap.

Kerusakan ini dapat terganggunya aliran air irigasi ke bagian hilir. Hal ini berpengaruh pada perbandingan antara debit tersedia dengan debit kebutuhan. Semakin tinggi nilai faktor kerusakan akan memberikan produksi tanaman yang semakin tinggi pula. Namun demikian dana rehabilitasi yang tersedia belum tentu mencukupi untuk seluruh kebutuhan. Perlu dilakukan analisa skala prioritas sehingga dana yang tersedia dapat dimanfaatkan dengan sebaik baiknya. Adapun tujuan dari penelitian yaitu untuk mengetahui tingkat kerusakan yang terjadi di Daerah Irigasi Bengawan Jero dan mengetahui skala prioritas rehabilitasi kerusakan Daerah Irigasi Bengawan Jero.

\section{METODE PENELITIAN}

Lokasi penelitian terletak di Daerah Irigasi Bengawan Jero dalam Wilayah Kerja 
Administrasi Kecamatan Karangbinangun, Kabupaten Lamongan. DI Bengawan jero berada di bawah pengelolaan Satuan Kerja Balai PSDA Bengawan Solo, Dinas PSDA Propinsi Jawa Timur Fungsi Daerah Irigasi Bengawan Jero adalah untuk mengairi sawah di Desa Kuro Kecamatan Karangbinangun dengan luas Baku Sawah 9986 Ha.

Studi ini melibatkan beberapa parameter yang digunakan untuk pertimbangan dalam pengambilan keputusan. Parameter tersebut antara lain: kebutuhan air irigasi untuk tanaman, ketersediaan air (debit andalan) dan kerusakan jaringan irigasi. Skala prioritas rehabilitasi menggunakan AHP dan prediksi produksi tanaman menggunakan faktor $\mathrm{k}$. Urutan langkah kerja dalam studi ini mencakup beberapa tahap, yaitu:

1) Pengumpulan data

a. Data kerusakan jaringan irigasi

b. Data estimasi kebutuhan dana rehabilitasi

c. Data teknis Daerah Irigasi Bengawan Jero

d. Data luas daerah layan

e. Data pola tanam

f. Data debit air

2) Tahap Analisis Data

a. Perhitungan debit andalan

b. Perhitungan kebutuhan air

3) Tahap Model Analisis
a. Pembobotan terhadap tiap kriteria
b. Penilaian tiap alternatif terhadap tiap kriteria

4) Tahap Perhitungan AHP (Analitical Hierarchy Process)

\section{HASIL DAN PEMBAHASAN \\ Hujan Efektif (Re)}

Perhitungan hujan efektif dalam penelitian ini dengan mengikuti pedoman Metode Tahun Dasar.

Tabel 1. Hujan Efektif Bulanan

\begin{tabular}{ccc}
\hline \multirow{2}{*}{ Bulan } & Hujan Efektif & Hujan Efektif \\
\cline { 2 - 3 } & $(\mathrm{mm})$ & $(\mathrm{mm} / \mathrm{hari})$ \\
\hline Nop I & 0,00 & 0,00 \\
Nop II & 38,00 & 2,53 \\
Des I & 54,00 & 3,38 \\
\hline
\end{tabular}

\begin{tabular}{lcc}
\hline \multirow{2}{*}{ Bulan } & Hujan Efektif & Hujan Efektif \\
\cline { 2 - 3 } & $(\mathrm{mm})$ & $(\mathrm{mm} /$ hari $)$ \\
\hline Des II & 120,00 & 8,00 \\
Jan I & 91,00 & 6,07 \\
Jan II & 135,00 & 8,44 \\
Feb I & 103,00 & 6,87 \\
Feb II & 124,00 & 9,54 \\
Mar I & 0,00 & 0,00 \\
Mar II & 54,00 & 3,38 \\
April I & 133,00 & 8,87 \\
April II & 77,00 & 5,13 \\
Mei I & 76,00 & 5,07 \\
Mei II & 39,00 & 2,44 \\
Juni I & 0,00 & 0,00 \\
Juni II & 0,00 & 0,00 \\
Juli I & 0,00 & 0,00 \\
Juli II & 0,00 & 0,00 \\
Agust I & 0,00 & 0,00 \\
Agust II & 0,00 & 0,00 \\
Sep I & 0,00 & 0,00 \\
Sep II & 0,00 & 0,00 \\
Okt I & 0,00 & 0,00 \\
Okt II & 0,00 & 0,00 \\
\hline
\end{tabular}

\section{Kebutuhan Air Untuk Irigasi}

Pada penerapan di lapangan, dalam penentuan berapa besarnya kebutuhan air untuk tanaman berpedoman pada IP3A (Induk Perkumpulan Pemakai Air) yang besarnya adalah sebagai berikut:

Tabel 2. Kebutuhan Air menurut IP3A

\begin{tabular}{lc}
\hline Jenis Tanaman & L/dt/ha \\
\hline Padi & \\
a. Pengolahan tanah dan persemaian & 1.25 \\
b. Pertumbuhan dan pemasakan & 0.725 \\
\hline Tebu & \\
a. Pengolahan tanah dan persemaian & 0.85 \\
b. Tebu muda (MT 1) & 0.36 \\
c. Tebu tua (MT 2) & 0.125 \\
\hline Palawija & \\
a. Yang perlu banyak air & 0.3 \\
b. Yang perlu sedikit air & 0.2 \\
\hline
\end{tabular}

Berpedoman pada tabel di atas maka perhitungan besarnya kebutuhan air per jenis tanaman adalah sebagai berikut:

Kebutuhan air untuk Padi

a. Jadual tanam periode mulai tanam 1 Nopember 2016

b. Penggunaan konsumtif $($ Etc $)=1.25 \mathrm{~L} / \mathrm{dt} / \mathrm{ha}$

c. Hujan efektif $(\mathrm{Re})=0 \mathrm{~mm}$

d. Kebutuhan air netto(NFR) 


$$
\begin{aligned}
\mathrm{NFR} & =\mathrm{Etc}-\mathrm{Re} \\
& =1.25-0 \\
& =1.25 \mathrm{lt} / \mathrm{dt} / \mathrm{ha}
\end{aligned}
$$

e. Kebutuhan air untuk irigasi (IR)

$$
\begin{aligned}
\text { IR } & =\text { NFR } / \mathrm{e} \\
& =1.25 / 65 \% \\
& =1.923 \mathrm{lt} / \mathrm{dt} / \mathrm{ha}
\end{aligned}
$$

\section{Tingkat Kerusakan Saluran}

Besarnya kerusakan pada tiap-tiap sub sistem dihitung dari besarnya penurunan volume saluran yang diakibatkan oleh sedimen ditambah dengan berkurangnya panjang saluran yang diakibatkan oleh saluran yang longsor.

Tabel 3. Kerusakan Fungsi Saluran

\begin{tabular}{cccc}
\hline \multirow{2}{*}{$\begin{array}{c}\text { Nama } \\
\text { Saluran }\end{array}$} & \multicolumn{3}{c}{ Kerusakan } \\
\cline { 2 - 4 } & Sedimen & $\begin{array}{c}\text { Panjang } \\
\text { Saluran }\end{array}$ & Total \\
\hline SubSitem 01 & 0,22 & 0,01 & 0,23 \\
SubSitem 02 & 0,23 & - & 0,23 \\
SubSitem 03 & 0,25 & - & 0,25 \\
SubSitem 04 & 0,48 & 0,02 & 0,50 \\
SubSitem 05 & 0,67 & 0,01 & 0,68 \\
SubSitem 06 & 0,52 & - & 0,52 \\
SubSitem 07 & 0,44 & - & 0,44 \\
SubSitem 08 & 0,54 & - & 0,54 \\
SubSitem 09 & 0,70 & - & 0,70 \\
SubSitem 10 & 0,42 & - & 0,42 \\
SubSitem 11 & 0,65 & - & 0,65 \\
\hline
\end{tabular}

Sumber : Balai PSDA

\section{Penilaian Kriteria}

Menurut Saaty dalam Marimin (2004), pada prinsip kerja AHP kriteria dinilai melalui perbandingan berpasangan untuk berbagai persoalan, skala 1 sampai 9 adalah skala terbaik dalam mengekspresikan pendapat.

Tabel 4. Skala Perbandingan Nilai Kriteria

\begin{tabular}{cl}
\hline Nilai & Keterangan \\
\hline 1 & $\begin{array}{l}\text { Kriteria / alternatif A sama } \\
\text { penting dengan kriteria / } \\
\text { alternatif B }\end{array}$ \\
\hline 3 & $\begin{array}{l}\text { Kriteria / alternatif A sedikit } \\
\text { lebih penting dari kriteria / } \\
\text { alternatif B }\end{array}$ \\
\hline 5 & $\begin{array}{l}\text { Kriteria / alternatif A jelas } \\
\text { lebih penting dari kriteria / } \\
\text { alternatif B }\end{array}$ \\
\hline 7 & $\begin{array}{l}\text { Kriteria / alternatif A sangat } \\
\text { jelas lebih penting dari kriteria } \\
\text { / alternatif B }\end{array}$ \\
\hline $\begin{array}{l}\text { Kriteria / alternatif A mutlak } \\
\text { lebih penting dari kriteria / } \\
\text { alternatif B }\end{array}$ \\
\hline Apabila ragu-ragu antara dua \\
nilai yang berdekatan
\end{tabular}

\section{Debit Inflow Andalan}

Penentuan debit inflow andalan Daerah Irigasi Bengawan Jero dihitung berdasarkan rumus Weibull yang kemudian diterapkan oleh Gumbell. Setelah data diurutkan dari nilai

\begin{tabular}{|c|c|c|c|c|c|c|c|c|c|c|c|c|}
\hline & \multicolumn{2}{|c|}{ Nov } & \multicolumn{2}{|c|}{ Des } & \multicolumn{2}{|c|}{ Jan } & \multicolumn{2}{|c|}{ Peb } & \multicolumn{2}{|c|}{ Mar } & \multicolumn{2}{|c|}{ April } \\
\hline & I & II & I & II & I & II & I & II & I & II & I & II \\
\hline \multirow[t]{3}{*}{ Debit lt/dt } & 760.4 & 397.4 & 649 & 1113 & 1063.4 & 1075.4 & 2326 & 2414 & 1525.4 & 1535 & 2118.2 & 2119 \\
\hline & & Mei & & Jun & & ul & & gt & $\mathrm{Se}$ & & Okt & \\
\hline & I & II & 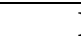 & Il & I & II & I & II & $\mathbf{I}$ & II & I & II \\
\hline Debitlt/dt & 1326. & 966. & 7 & 562 & 423 & 325.8 & 273.8 & 233.2 & 206.2 & 196 & 227.65 & 581 \\
\hline
\end{tabular}
debit Inflow terbesar sampai dengan yang terkecil pada bulan november, maka nilai peluangnya adalah:

$$
\begin{aligned}
P(x m) & =\frac{m}{n+1} \\
& =\frac{1}{10+1}=0,0909
\end{aligned}
$$

Debit Inflow Andalan 
Penilaian alternatif dilakukan dengan cara memberikan nilai bobot masing-masing daerah yang ditinjau untuk setiap kriterianya Skala yang digunakan adalah nilai 1 sampai 10. Hasil analisis maupun data alternatif untuk tiap kriteria dimasukkan kedalam beberapa interval nilai. Setiap interval nilai yang digunakan diberikan bobot nilai dari 1 sampai 10, berdasarkan pada tingkat kepentingannya dari yang terburuk sampai yang terbaik.

\section{a. Panjang Saluran}

Penilaian alternatif panjang saluran didasarkan atas data sekunder yang diperoleh dari kantor Balai PSDA Bengawan Solo yang kemudian dilakukan pembobotan dengan memberikan nilai dari yang terkecil hingga yang terbesar dengan interval pembobotan sebagai berikut :

Tabel 5. Pembobotan Panjang Saluran

\begin{tabular}{cc}
\hline Bobot & Panjang Saluran $(\mathrm{km})$ \\
\hline 1 & $<0,340$ \\
2 & $0,340-1,153$ \\
3 & $1,153-1,965$ \\
4 & $1,965-2,778$ \\
5 & $2,778-3,590$ \\
6 & $3,590-4,403$ \\
7 & $4,403-5,215$ \\
8 & $5,215-6,028$ \\
9 & $6,028-6,840$ \\
10 & $6,840<$ \\
\hline
\end{tabular}

Setelah dilakukan pembobotan dilakukan penilain Panjang Saluran pada masing -masing daerah Sub Sistem, dengan hasil sebagai berikut :

Tabel 6. Hasil Pembobotan Panjang Saluran

\begin{tabular}{ccc}
\hline $\begin{array}{c}\text { Sub } \\
\text { Sistem }\end{array}$ & $\begin{array}{c}\text { Panjang } \\
\text { Saluran }(\mathrm{km})\end{array}$ & Pembobotan \\
\hline 1 & 3,86 & 6 \\
2 & 1,54 & 3 \\
3 & 1,40 & 3 \\
4 & 0,83 & 2 \\
5 & 4,30 & 6 \\
6 & 2,34 & 4 \\
7 & 4,64 & 7 \\
\hline
\end{tabular}

\begin{tabular}{ccc}
\hline $\begin{array}{c}\text { Sub } \\
\text { Sistem }\end{array}$ & $\begin{array}{c}\text { Panjang } \\
\text { Saluran }(\mathrm{km})\end{array}$ & Pembobotan \\
\hline 8 & 0,34 & 2 \\
9 & 0,34 & 5 \\
10 & 6,41 & 9 \\
11 & 6,84 & 9 \\
\hline
\end{tabular}

\section{b. Tingkat Kerusakan Jaringan Irigasi}

Kerusakan yang ditinjau pada jaringan irigasi disini adalah hasil rata-rata dari dua kerusakan saluran yaitu, sedimentasi dan pembersihan semak-semak. Tingkat kerusakan dari yang terendah sampai yang tertinggi di dipilah kemudian diberikan bobot nilai 1-10, kerusakan yang tinggi mendapatkan bobot yang besar sehingga kemungkinan dilakukan rehabilitasi juga besar.Pembobotan dilakukan berdasarkan bobot tingkat kerusakan sebagai berikut :

Tabel 7. Pembobotan menurut Tingkat Kerusakan

\begin{tabular}{|c|c|c|c|}
\hline Bobot & \multicolumn{3}{|c|}{ Skala Pembobotan } \\
\hline 1 & & $<$ & 0,23 \\
\hline 2 & 0,23 & - & 0,28 \\
\hline 3 & 0,28 & - & 0,33 \\
\hline 4 & 0,33 & - & 0,39 \\
\hline 5 & 0,39 & - & 0,44 \\
\hline Bobot & \multicolumn{3}{|c|}{ Skala Pembobotan } \\
\hline 6 & 0,44 & - & 0,49 \\
\hline 7 & 0,49 & - & 0,54 \\
\hline 8 & 0,54 & - & 0,59 \\
\hline 9 & 0,59 & - & 0,65 \\
\hline 10 & 0,65 & $<$ & \\
\hline
\end{tabular}

Setelah dilakukan pembobotan menurut tingkat kerusakan selanjutnya dilakukan penilain tingkat kerusakan pada masingmasing daerah Sub Sistem, dengan hasil sebagai berikut :

Tabel 8. Hasil Pembobotan Tingkat Kerusakan

\begin{tabular}{ccc}
\hline No Saluran & Kerusakan & Bobot \\
\hline 1 & 0,23 & 2 \\
2 & 0,23 & 2 \\
3 & 0,25 & 2 \\
4 & 0,50 & 6 \\
\hline
\end{tabular}




\begin{tabular}{ccc}
\hline No Saluran & Kerusakan & Bobot \\
\hline 5 & 0,68 & 9 \\
6 & 0,52 & 6 \\
7 & 0,44 & 7 \\
8 & 0,54 & 5 \\
9 & 0,70 & 9 \\
10 & 0,42 & 5 \\
11 & 0,65 & 9
\end{tabular}

\section{KESIMPULAN}

Berdasarkan hasil analisa dan pembahasan pada Bab sebelumnya, maka dapat ditarik kesimpulan bahwa analisis skala prioritas rehabilitas Daerah Irigasi Bengawan Jero dengan menggunakan Analitical Hierarchy Process (AHP) memberikan prioritas pertama pada sub sistem $05=0,68$. Prioritas selanjutnya adalah sub sistem $07=$ 0,44 , sub sistem $01=0,23$, sub sistem $09=$ 0,70 , sub sistem $03=0,25$, sub sistem $10=$ 0,42 , sub sistem $11=0,65$, sub sistem $06=$ 0,52 , sub sistem $08=0,54$, sub sistem $04=$ 0,50 dan prioritas terakhir adalah sub sistem $02=0,23$. Ditentukan 11 alternatif rehabilitasi yang didasarkan pada skala prioritas hasil analisis Analitical Hierarchy Process (AHP). Pemilihan alternatif rehabilitasi disesuaikan dengan dana yang tersedia. Apabila dana yang tersedia tidak mencukupi untuk merahabilitasi Daerah Irigasi Bengawan Jero secara keseluruhan maka rehabilitasi dapat dititik beratkan pada saluran primer saja. Apabila dana yang tersedia lebih dari cukup untuk merehabilitasi saluran primer maka saluran sekunder dapat direhabilitasi pula.

\section{REFERENSI}

Anonim. 2007. Peraturan Menteri Pekerjaan Umum No.32/PRT/M/2007 Tentang Pedoman Operasi dan Pemeliharaan

Kunaifi, A. A. 2010. Pola Penyediaan Air DI. Tibunangka dengan Sumur Renteng pada Sistem Suplesi Renggung. Tesis tidak dipubikasikan. Universitas Brawijaya Malang.

Marimin. 2004, Teknik dan Aplikasi Pengam-bilan Keputusan Kriteria Majemuk, Gramedia, Jakarta.
Saaty, Thomas L.1993. Pengambilan Keputusan bagi Para Pemimpin. Penerbit Pustaka Binaman Pressindo, Jakarta.

Soewarno. 1995. Hidrologi Untuk Teknik. Penerbit Nova, Bandung.

Triatmodjo, Bambang. 2010. Hidrologi Terapan. Cetakan kedua. Beta Offset. Yogyakarta. 
Halaman ini sengaja dikosongkan 